Annales Geophysicae (2003) 21: 205-220 (C) European Geosciences Union 2003

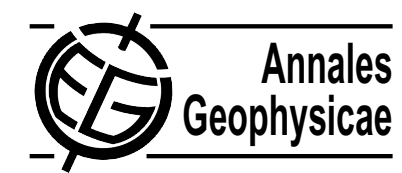

\title{
A one-way nested eddy resolving model of the Aegean and Levantine basins: implementation and climatological runs
}

\author{
G. Korres and A. Lascaratos \\ Department of Applied Physics, University of Athens, Athens, Greece \\ Received: 7 June 2001 - Revised: 7 November 2001 - Accepted: 21 January 2002
}

\begin{abstract}
The present study deals with the implementation of an eddy resolving model of the Levantine and Aegean basins and its one-way nesting with a coarse resolution $\left(1 / 8^{\circ} \times 1 / 8^{\circ}\right)$ global Mediterranean general circulation model. The modelling effort is done within the framework of the Mediterranean Forecasting System Pilot Project as an initiative towards real-time forecasting within the eastern Mediterranean region.

The performed climatological runs of the nested model have shown very promising results on the ability of the model to capture correctly the complex dynamics of the area and at the same time to demonstrate the skill and robustness of the nesting technique applied.

A second aim of this study is to prepare a comprehensive climatological surface boundary conditions data set for the Mediterranean Sea. This data set has been developed within the framework of the same research project and is suitable for use in ocean circulation models of the Mediterranean Sea or parts of it. The computation is based on the ECMWF 6-h atmospheric parameters for the period 1979-1993 and a calibrated set of momentum and heat flux bulk formulae resulted from previous studies for the Mediterranean region.
\end{abstract}

Key words. Oceanography: general (numerical modelling); physical (general circulation; air-sea interactions)

\section{Introduction}

Within the framework of the Mediterranean Forecasting System Pilot Project (hereafter MFSPP), an eddy resolving ocean model of the Aegean and Levantine basins (ALERMO) has been developed. ALERMO, with a horizontal resolution of $1 / 20^{\circ} \times 1 / 20^{\circ}$, acts as an intermediate between the global Mediterranean general circulation model (Roussenov et al., 1995; Pinardi et al., 1997; Pinardi and Masetti, 2000), hereafter OGCM, and the various eastern Mediterranean high-resolution shelf models developed

Correspondence to: G. Korres (gerasim@oc.phys.uoa.gr) within the same project. Such a modelling effort is rather challenging for the oceanography of the eastern Mediterranean since it was the first time models with such a high resolution have been implemented within this region. On the other hand, the whole effort prepares the prerequisites for the operational oceanography of the region, which will be the near future phase of the project.

In this paper, we present the development of the ALERMO model, the nesting technique with the OGCM, along with the results from the climatological runs of the model. Previous modelling studies in this area address the problem of the Levantine Intermediate Water (LIW) formation process (Lascaratos and Nittis, 1998), using the Princeton primitive equation model (POM) and the simulation and understanding of the internal dynamics of the area, using a quasi-geostrophic modelling approach (Robinson and Golnaraghi, 1993; Golnaraghi, 1993). Both modelling efforts and a subsequent one by Lascaratos et al. (1999), attempting to simulate the recent changes in the deep thermohaline circulation of the eastern Mediterranean, have been designed in a stand-alone model context. In this study, for the first time we address the problem of nesting a high resolution general circulation model of the whole eastern Mediterranean with a coarse resolution global Mediterranean general circulation model (OGCM). Nesting procedures, although quite old and well set within the weather forecast context, are still open research issues in operational oceanography. Even for the scales of the Mediterranean basin, computational constraints still make the simulation of high resolution domains quite a significant challenge. The rather simple nesting technique adopted in this study allows for the high resolution model (ALERMO) to have simultaneous independent radiative boundary conditions and dependent nested boundary conditions provided by the OGCM. Such a nesting technique guarantees free passage of unwanted wave energy through the boundary of the high resolution model and at the same time modifies the inner solution according to the coarse resolution model (OGCM) dynamics. Although this nesting implementation is done here on a climatological basis, ongoing work (to be presented 


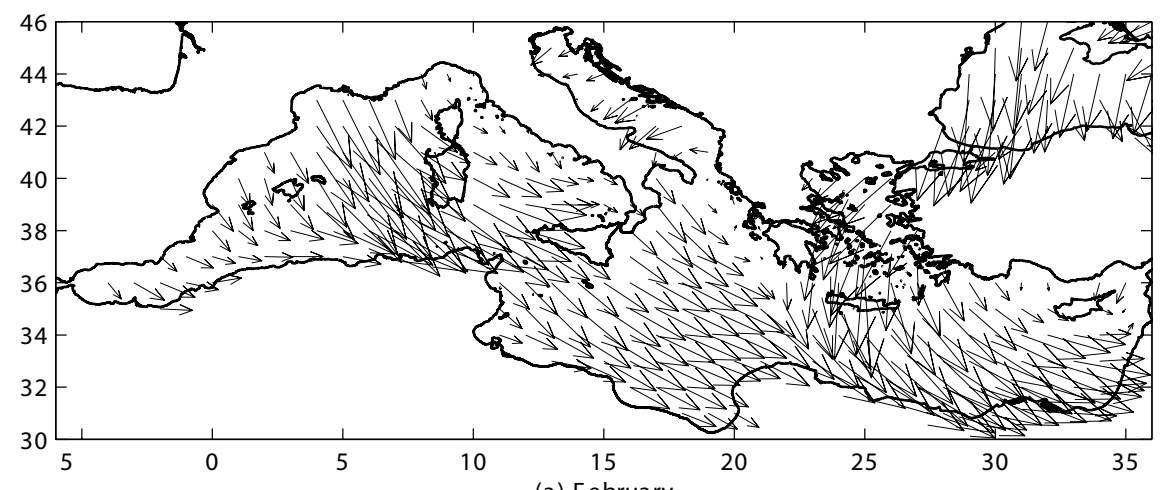

(a) February

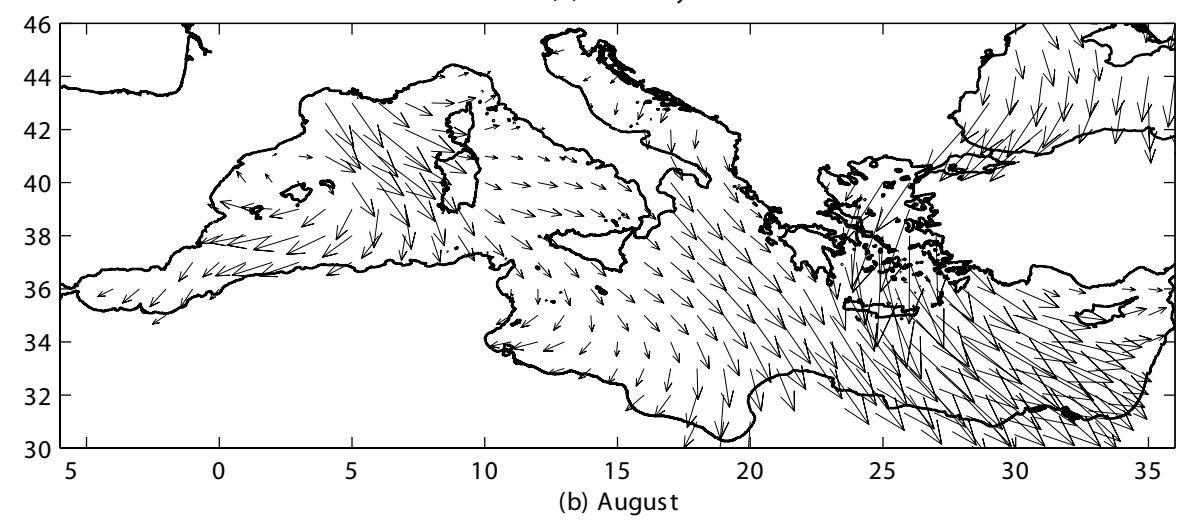

Fig. 1. (a) Wind stress field for February (b) Wind stress field for August. in a forthcoming paper) in a July/September 1999 hindcast simulation experiment, using 6-h atmospheric forcing, has demonstrated its robustness.

The second aim of this study is the development of a "perpetual year" surface boundary conditions data set (wind stresses, net solar and long-wave radiation, latent and sensible heat flux) for the whole Mediterranean, to be used by the OGCM, as well as by all intermediate and shelf models within the same project. The study of Castellari et al. (1998) has dealt with the similar problem of formulating a calibrated set of heat flux bulk formulae to be used by the Mediterranean basin general circulation models. In the same context, Garrett et al. (1993) examined and estimated the Mediterranean heat budget using the COADS (Slutz et al., 1985) 1946-1988 data set. In the latter study, latent and sensible heat fluxes are partially estimated from instantaneous values, while the turbulent exchange coefficients and the long-wave radiation are computed using monthly mean values. In this paper, we apply Castellari et al. (1998) suggested "best set" of bulk formulae to the ECMWF high-frequency (6-h) atmospheric data set, covering a 15-year period (January 1979December 1993), to derive new monthly heat and momentum flux estimates for the Mediterranean basin. As an alternative, we have substituted Kondo's scheme (suggested by Castellari et al., 1998) for the computation of latent and sensible heat flux, with Budyko's bulk formula (Budyko, 1963), originally proposed to be used with monthly values of atmospheric parameters. As explained in Sect. 2, this was done in order to compensate for the known relatively low wind speed values of the 15-year ECMWF data set.
The paper has been organized as follows. In Sect. 2 we present the methodology followed for the preparation of the new surface boundary conditions data set. Results are discussed and intercompared with previous similar studies. The next section deals with the ALERMO model setup, the implementation of the nesting open boundary conditions and the climatological runs of the model. A thorough description of the eastern Mediterranean climatological circulation picture, as revealed by the model results, is also given here. Finally, in Sect. 4 we offer a brief summary of the main results.

\section{Preparation of the climatological atmospheric forcing}

In this section, we present the procedures followed in order to prepare the climatological atmospheric forcing data set, which was used to force the OGCM, intermediate and shelf models within the project. This new atmospheric forcing data set consists of heat flux fields and wind stress components on a monthly basis, derived from the ECMWF 1979-1993 6-h re-analysis atmospheric parameters on a regular $1^{\circ} \times 1^{\circ}$ grid. Below we explain in detail the methodology we used for the derivation of each of the different heat flux components and the wind stress fields.

\subsection{Wind stress components}

The calculation of the climatological wind stress fields is based on the transformation of the 6-h ECMWF wind velocity data at $10 \mathrm{~m}$, to the zonal/meridional components of 

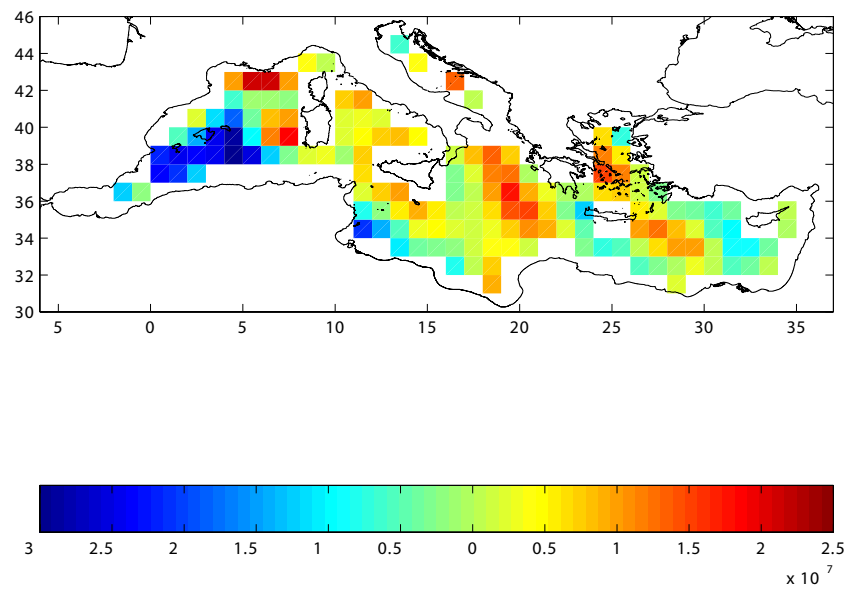

Fig. 2. Wind stress curl difference between February and August. Units are $\mathrm{Nt} / \mathrm{m}^{3}$.

the wind stress exerted on the sea surface, according to the formula:

$$
\boldsymbol{\tau}=\rho_{A} C_{D}|\boldsymbol{W}| \boldsymbol{W},
$$

where $\rho_{A}$ is the air density, $\boldsymbol{W}$ is the wind velocity and $C_{D}$ is the drag coefficient, which is calculated every $6 \mathrm{~h}$ as a function of wind speed and air-sea temperature difference through a polynomial approximation given by Hellerman and Rosenstein (1983). SST data are taken from Reynolds $1^{\circ} \times 1^{\circ}$ monthly $1979-1993$ data set (linearly interpolated every $6 \mathrm{~h}$ ), while air temperature data at $2 \mathrm{~m}$ above sea surface are taken from the ECMWF 1979-1993 re-analysis data. Finally, the air density in Eq. (1) is calculated as a function of air temperature and relative humidity.

The 6-h zonal and meridional components of the wind stress time series, as computed by Eq. (1), are then averaged in time, in order to form monthly climatological fields for the Mediterranean region. In Fig. 1 we show the wind stress field for a typical winter and summer month. The most pronounced features during wintertime are the strong Mistral winds over the western Mediterranean, blowing from northwest, and the northeasterlies over the Aegean Sea changing progressively to northwesterlies over the eastern Levantine basin. Quasi-zonal winds prevail over the Ionian Sea, while the Bora wind pattern is evident within the Adriatic Sea. The summer regime is characterized by differences in the wind stress curl pattern over large parts of the basin, as shown in Fig. 2, presenting the difference in the wind stress curl between the peaks of the winter (February) and summer (August) seasons. Differences are most pronounced over the western Mediterranean and the Ionian Sea. However, within the Levantine basin and the Aegean Sea, the seasonal changes are perceptibly weaker. It is worth mentioning here that the monthly wind stress fields produced with this particular method from the ECMWF re-analysis wind velocity data, compare very well with the wind stress fields, as calculated by Hellerman and Rosenstein (1983) for the Mediterranean region.
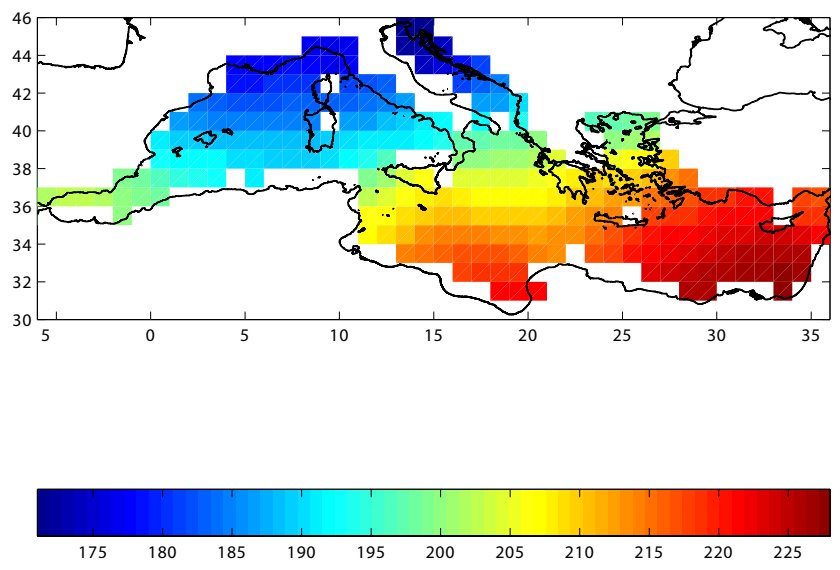

Fig. 3. Mean annual distribution of net short-wave radiation at the sea surface (in $\mathrm{W} / \mathrm{m}^{2}$ ).

\subsection{Solar radiation}

The calculation of the absorbed solar radiation at the Mediterranean Sea surface is based on the Reed formula (Reed, 1977), as already done in Rosati and Miyakoda, (1988) for the global ocean, Garrett et al. (1993) and Castellari et al. (1998) for the Mediterranean region:

$Q_{s}=Q_{T O T}(1-0.62 C+0.0019 \beta)(1-\alpha)$,

where $Q_{\text {tot }}$ is the total solar radiation reaching the ocean surface under a clear sky, $\beta$ is the solar noon altitude and $\alpha$ is the sea surface albedo. The cloud cover $C$ in Eq. (2) is taken from COADS $1^{\circ} \times 1^{\circ}$ monthly data set for the period 1979-1993 instead of ECMWF re-analysis data. An intercomparison (not shown) between basin average ECMWF (as derived from 6-h data) and COADS observational cloud cover monthly climatologies shows a systematic underestimation of the cloud coverage (especially during the cold season) by the ECMWF data set. This is in agreement with Jakob (1999), who evaluated the cloud cover in the ECMWF re-analysis data for the period 1983-1990 and pointed out an underestimation of extratropical cloud cover over the oceans by $10 \%-15 \%$.

The linear dependence of the Reed formula on cloud cover permits us, without significant error, to apply this formula using monthly averages of cloud cover.

Monthly values of solar insolation at each grid point are estimated after appropriate averaging of hourly values, as computed according to Eq. (2).

In Fig. 3 we show the mean annual pattern of the net shortwave radiation over the Mediterranean basin. It is characterized by a north-south gradient, with maximum solar heating occurring over the southeasternmost part of the Levantine basin. The basin's mean annual solar radiation absorbed by the Mediterranean basin amounts to $202 \mathrm{~W} / \mathrm{m}^{2}$, which is the same value as Castellari et al. (1998) calculated. 


\subsection{Net long-wave radiation}

Bignami et al. (1995) proposed a bulk formula for the calculation of net long-wave radiation at the sea surface, which was strictly derived from regression to long-wave radiation measurements within the western Mediterranean. Up to now, this has been the most appropriate formula for the calculation of long-wave radiation within the Mediterranean Sea, although one could argue that this formula is more representative of the western Mediterranean oceanic and meteorological conditions. Actually, very recently, Schiano et al. (2000) have stressed the importance of adjusting the Bignami formula to the different areas of the Mediterranean Sea or even inventing a new bulk formulae by taking into account the complex climatic conditions prevailing over the Mediterranean region. However, such an adjustment is out of the scope of the present paper, since it requires an extensive data set of direct net long-wave radiation measurements over the whole Mediterranean basin.

Following Bignami et al. (1995), the net long-wave radiation at the sea surface is given by:

$$
\begin{gathered}
Q_{B}=\epsilon \sigma T_{s}^{4}-\left[\sigma T_{A}^{4}\left(0.653+0.00535 e_{A}\right)\right] \\
\cdot\left(1+0.1762 C^{2}\right)
\end{gathered}
$$

where $\epsilon, \sigma$ are the sea surface emissivity and the StefanBoltzman constant, respectively, $C$ is the cloud cover, $e_{A}$ is the atmospheric vapor pressure and $T_{S}, T_{A}$ are the SST and air temperature at $2 \mathrm{~m}$ height above the sea surface, respectively. The atmospheric vapor pressure is proportional to the relative humidity $r$ :

$e_{A}=r e_{\mathrm{SAT}}\left(T_{A}\right)$,

where $e_{\mathrm{SAT}}$ is the atmospheric saturation vapor pressure, computed through a polynomial approximation as a function of air temperature (Lowe, 1977).

The computation of $Q_{B}$ is done every $6 \mathrm{~h}$, using the 1979 -1993 ECMWF atmospheric parameters of air temperature and relative humidity, and SST data from Reynolds' (Reynolds, 1994) 1979-1993 monthly data set $\left(1^{\circ} \times 1^{\circ}\right)$ after it has been linearly interpolated in time. We should point out here that a bulk formula with a linear dependence on cloud cover should be preferable to be used when monthly values of cloud cover are available (COADS cloud cover data). However, the Bignami formula, being the only one tuned within the Mediterranean region, is our unique choice for the estimation of the net long-wave radiation, although we expect some possible error due to the type (monthly versus instantaneous) of cloud cover data we used.

Monthly fields of $Q_{B}$ are obtained by appropriate averaging of the 6-h time series obtained by Eq. (3) at each grid point. On a yearly basis, Bignami's formula presents an increased net long-wave heat loss over the northern parts of the Mediterranean Sea and within the eastern Levantine basin. The basin's average time series of $Q_{B}$ (not shown) is characterized by a maximum of $100 \mathrm{~W} / \mathrm{m}^{2}$ during January and a minimum value of $80 \mathrm{~W} / \mathrm{m}^{2}$ during August, while the mean annual value of net long-wave radiation is $90.3 \mathrm{~W} / \mathrm{m}^{2}$.

\subsection{Latent and sensible heat flux}

The latent $Q_{e}$ and sensible $Q_{h}$ heat fluxes are computed according to the classical bulk aerodynamic formulae (Rosati and Miyakoda, 1988; Castellari et al., 1998):

$$
\begin{aligned}
Q_{e} & =\rho_{A} L_{V} C_{E}|\boldsymbol{W}|\left[e_{\mathrm{SAT}}\left(T_{S}\right)-r e_{\mathrm{SAT}}\left(T_{A}\right)\right] \frac{0.622}{p_{A}} \\
Q_{h} & =\rho_{A} c_{p} C_{H}|\boldsymbol{W}|\left(T_{S}-T_{A}\right),
\end{aligned}
$$

where $\rho_{A}$ is the density of moist air (computed as a function of air temperature and relative humidity), $c_{p}$ is the specific heat capacity of atmospheric air, $p_{A}$ is the atmospheric pressure and $\boldsymbol{W}$ represents the horizontal wind velocity vector at $10 \mathrm{~m}$ above sea surface. The latent heat of vaporization, $L_{V}$, is calculated as a function of sea surface temperature (Gill, 1982). $C_{E}$ and $C_{H}$ are the turbulent exchange coefficients both taken equal to $2.1 \times 10^{-3}$ in the "neutral Budyko scheme", as proposed by (Budyko, 1963). Budyko imposed these large values for the turbulent exchange coefficients, since he had to deal with monthly values of the atmospheric parameters that inevitably lead to an underestimation of the turbulent heat fluxes through the air-sea interface. In the scheme known as "Kondo scheme" (Kondo, 1975), the turbulence exchange coefficients in diabatic conditions (stable or unstable) are estimated in terms of the sea-air temperature difference and the wind speed, along with an index of atmospheric stability that nonlinearly modulates them. Castellari et al. (1998), using twice daily NCEP 1980-1988 atmospheric data $\left(1^{\circ} \times 1^{\circ}\right)$, COADS monthly cloud cover data $\left(1^{\circ} \times 1^{\circ}\right)$ for the same period and Reynolds (Reynolds, 1994) 1980-1988 monthly SST $\left(1^{\circ} \times 1^{\circ}\right)$, have selected the Kondo scheme as the most appropriate for the computation of latent and sensible heat flux. In particular, taking into consideration the terrestrial branch of the water cycle of the Mediterranean, they estimate the Mediterranean evaporation rate to range between $1.32-1.57 \mathrm{~m} / \mathrm{yr}$, which corresponds to a range of $Q_{e}$ between 103-122 W/m ${ }^{2}$. The annual mean basin average value of $Q_{e}$ that they have obtained with the Kondo scheme is $122 \mathrm{~W} / \mathrm{m}^{2}$, while the neutral Budyko scheme resulted in a much higher value in their case $\left(170 \mathrm{~W} / \mathrm{m}^{2}\right)$ that had to be rejected on the grounds of the acceptable evaporation range.

In our case, we have estimated the latent and sensible heat flux using both schemes (i.e. the Kondo and the neutral Budyko scheme) and intercompare the results in terms of the acceptable evaporation range suggested by Castellari et al. (1998). For both schemes we form 6-h values of $Q_{e}$ and $Q_{h}$ using the ECMWF $1979-1993$ re-analysis data $\left(1^{\circ} \times 1^{\circ}\right)$ for the atmospheric parameters of air temperature, relative humidity and wind speed, while the cloud cover data are taken from the COADS 1979-1993 monthly cloud cover data $\left(1^{\circ} \times 1^{\circ}\right)$ and the SST from the Reynolds 1979-1993 monthly data set $\left(1^{\circ} \times 1^{\circ}\right)$. Finally, from the 6-h values of $Q_{e}$ and $Q_{h}$ we form a monthly mean data set with appropriate averaging. 

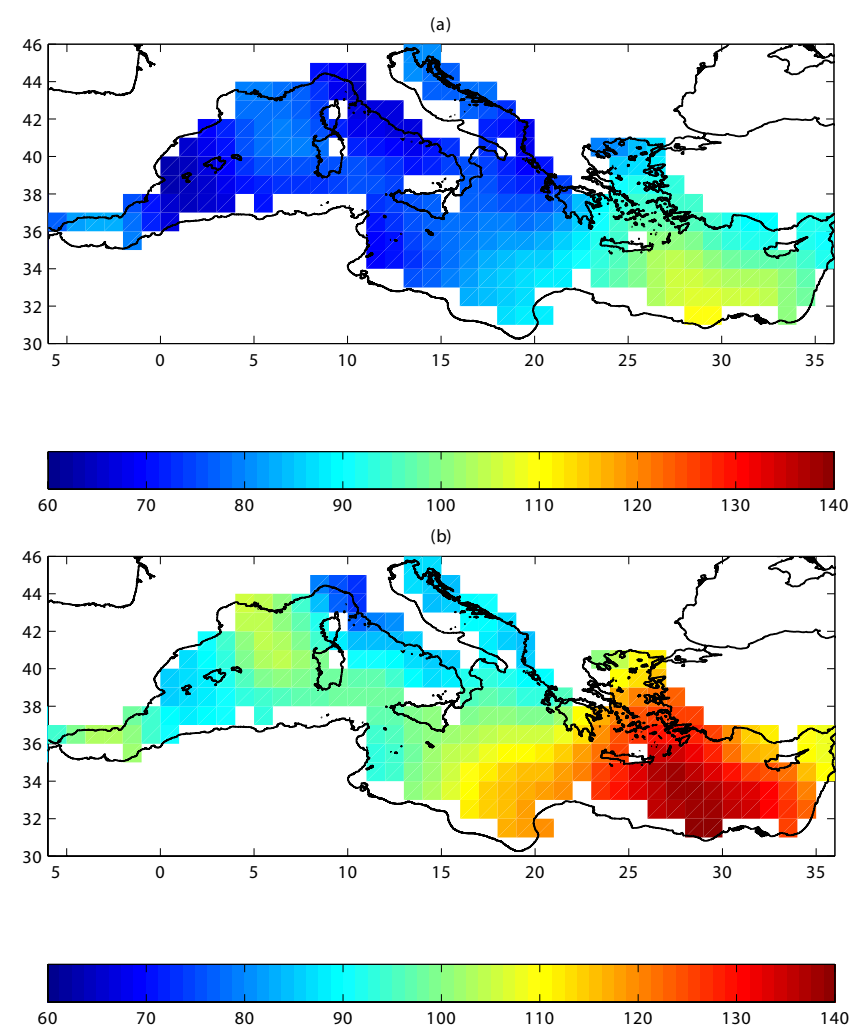

Fig. 4. Mean annual distribution of evaporative heat flux at the sea surface corresponding (a) to Kondo scheme and (b) to neutral Budyko scheme. Units are $\mathrm{W} / \mathrm{m}^{2}$.

Budyko's neutral scheme corresponds to a mean annual value of $106.2 \mathrm{~W} / \mathrm{m}^{2}$, which is within the acceptable range of values for the Mediterranean basin, while the Kondo scheme corresponds to a much lower value $\left(82.9 \mathrm{~W} / \mathrm{m}^{2}\right)$. The mean annual spatial patterns corresponding to the two schemes are shown in Fig. 4. The increased value of the turbulent exchange coefficient that the neutral Budyko scheme assumes compensates for the underestimated magnitude of the $10 \mathrm{~m}$ ECMWF winds and thus, produces a correct basin mean value for the latent heat flux. However, by inspecting Fig. 4b, it is evident that this scheme overestimates the evaporation rate over the eastern Levantine basin. On the other hand, the Kondo scheme leads to an underestimation of the evaporation rates over large parts of the Mediterranean basin.

\subsection{Net heat flux}

The net heat flux into the Mediterranean Sea consists of the solar insolation minus the net long-wave radiation and the latent and sensible heat fluxes:

$Q_{t}=Q_{s}-Q_{B}-Q_{e}-Q_{h}$.

The results of the different heat flux bulk formulae are summarized in Table 1 in terms of annual mean values. The Bignami formula for the computation of net long-wave radiation, combined with the Kondo scheme for the calculation of the latent and sensible heat flux, gives a positive
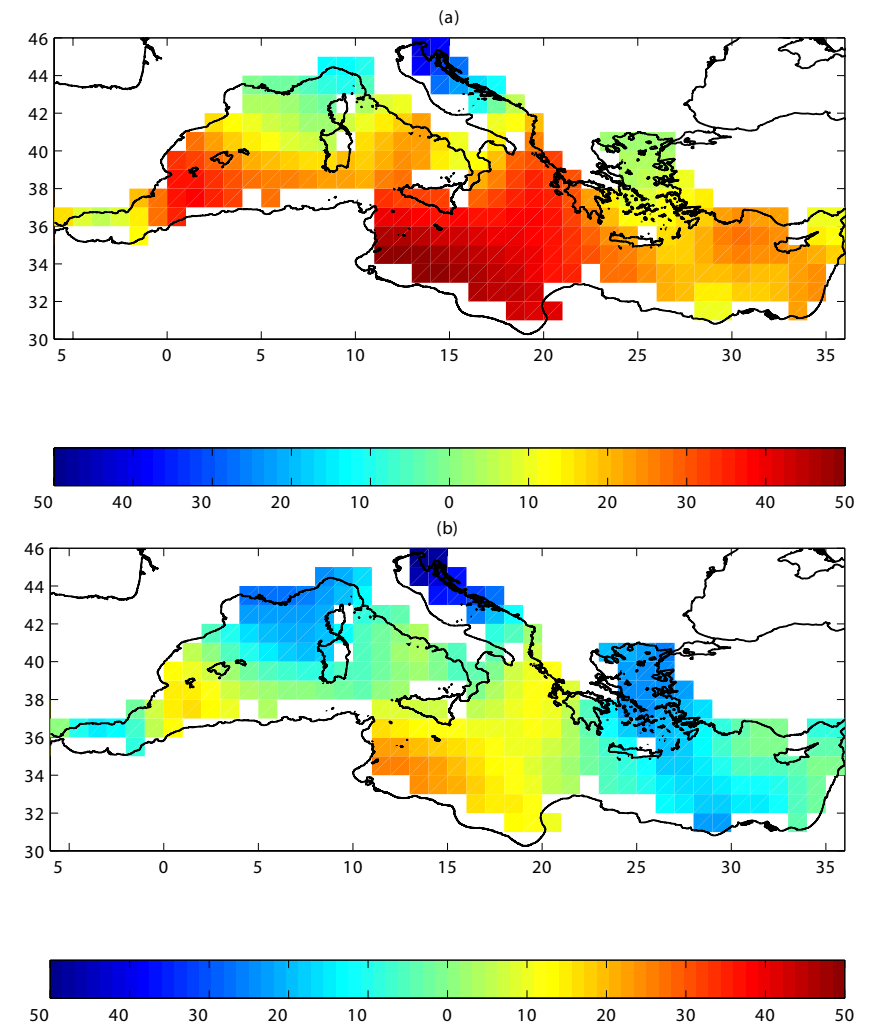

Fig. 5. Mean annual distribution of total heat flux at the sea surface corresponding (a) to Kondo-Bignami and (b) to Budyko-Kondo data set. Units are $\mathrm{W} / \mathrm{m}^{2}$.

$\left(+17.9 \mathrm{~W} / \mathrm{m}^{2}\right)$ heat budget for the Mediterranean. We will refer to this combination as the "Kondo-Bignami" data set. The spatial distribution of the mean annual net heat flux corresponding to the Kondo-Bignami data set is shown in Fig. 5a. The optimum combination of bulk formulae in terms of the widely accepted basin average annual heat budget for the Mediterranean basin $\left(-7 \mathrm{~W} / \mathrm{m}^{2}\right)$ consists of the neutral Budyko scheme for the computation of latent and sensible heat fluxes, along with the Bignami formula for the calculation of the net long-wave radiation (we call this the "BudykoBignami" data set). According to Table I, this particular combination amounts to an annual heat budget of $-7.2 \mathrm{~W} / \mathrm{m}^{2}$. In Fig. $5 \mathrm{~b}$ we show the spatial distribution of the net heat flux corresponding to the Budyko-Bignami data set. The pattern shown in this figure corresponds to a net heat loss over the Levantine and Aegean basins, the Adriatic Sea and the northwestern sector of the western Mediterranean basin. The Ionian basin presents an area of net heat gain, especially in its southwestern part. Comparison of Figs. 5a and b shows that the two data sets involve almost the same spatial structure apart from a positive offset of around $25 \mathrm{~W} / \mathrm{m}^{2}$ of the "Kondo-Bignami" data set. In a Mediterranean modelling perspective, such a positive offset can be corrected by the appropriate choice of a heat flux correction term, as will be shown in what follows. Finally, it is interesting to point out that both data sets (Budyko-Bignami and Kondo-Bignami) 
Table 1. Heat budget components estimated with different formulations

\begin{tabular}{|c|c|c|c|c|}
\hline Formulae & $Q_{s}\left(\mathrm{~W} / \mathrm{m}^{2}\right)$ & $Q_{B}\left(\mathrm{~W} / \mathrm{m}^{2}\right)$ & $Q_{e}\left(\mathrm{~W} / \mathrm{m}^{2}\right)$ & $Q_{h}\left(\mathrm{~W} / \mathrm{m}^{2}\right)$ \\
\hline Reed & 201.67 & & & \\
\hline Bignami & & 90.33 & & \\
\hline Neutral Budyko & & & 106.18 & 12.42 \\
\hline Kondo & & & 82.81 & 11.16 \\
\hline
\end{tabular}

have spatial scales comparable with the ones existing in the Garrett and Outerbridge (1993) results (based on COADS data), although these authors arrived at the correct global Mediterranean heat budget by reducing the short-wave radiation by $18 \%$.

\section{The numerical model}

\subsection{Model description}

The ALERMO model is based on the Princeton Ocean Model (POM), a primitive equation, 3-D circulation model. POM has been extensively described in the literature (Blumberg and Mellor, 1983, 1987; Oey et al., 1985a, b; Galperin and Mellor, 1990a, b; Mellor and Ezer, 1991, Horton et al., 1997; Lascaratos and Nittis, 1998) and is accompanied by a comprehensive user's guide (Mellor, 1998). It has been used previously in numerous coastal applications like the South Atlantic Bight (Blumberg and Mellor, 1983), Delaware Bay (Galperin and Mellor, 1990a, b), the Gulf of Mexico (Mellor and Blumberg, 1985), the Gulf Stream (Ezer and Mellor, 1992), the Mediterranean Sea (Zavatarelli and Mellor, 1995; Horton et al., 1997; Drakopoulos and Lascaratos, 1997), the Adriatic Sea (Zavatarelli and Pinardi, 1995) and the Levantine Sea (Lascaratos and Nittis, 1998), to list some of them.

The model has a bottom-following vertical sigma coordinate system, a free surface and a split mode time step. Potential temperature, salinity, velocity and surface elevation are prognostic variables. It solves the following equations for the ocean velocity $U_{i}=(U, V, W)$, potential temperature $T$ and salinity $S$ :

$$
\begin{aligned}
& \frac{\partial U_{i}}{\partial x_{i}}=0 \\
& \frac{\partial}{\partial t}(U, V)+\frac{\partial}{\partial x_{i}}\left[U_{i}(U, V)\right]+f(-V, U)= \\
& \quad-\frac{1}{\rho_{0}}\left[\frac{\partial p}{\partial x}, \frac{\partial p}{\partial y}\right]+\frac{\partial}{\partial z}\left[K_{M} \frac{\partial}{\partial z}(U, V)\right]+\left(F_{U}, F_{V}\right) \\
& \frac{\partial T}{\partial t}+\frac{\partial}{\partial x_{i}}\left[U_{i} T\right]=\frac{\partial}{\partial z}\left[K_{H} \frac{\partial T}{\partial z}\right]+F_{T} \\
& \frac{\partial S}{\partial t}+\frac{\partial}{\partial x_{i}}\left[U_{i} S\right]=\frac{\partial}{\partial z}\left[K_{H} \frac{\partial S}{\partial z}\right]+F_{S} .
\end{aligned}
$$

The hydrostatic approximation yields:

$$
\frac{p}{\rho_{0}}=g(n-z)+\int_{z}^{n} \frac{\rho-\rho_{0}}{\rho_{0}} g d z,
$$

where $n$ is the free surface elevation, $\rho_{0}$ is a reference density and $\rho=\rho(T, S, p)$ is the density calculated by an adaptation of the UNESCO equation of state by Mellor (1991b). The horizontal diffusion terms $F_{U}, F_{V}, F_{T}$ and $F_{S}$ in Eqs. (8), (9) and (10) are evaluated using the Smagorinsky (1963) horizontal diffusion formulation.

The vertical mixing coefficients $K_{M}$ and $K_{H}$ in Eqs. (8)(10) are computed according to the Mellor-Yamada 2.5 turbulence closure scheme (Mellor and Yamada, 1982).

The ALERMO model has one open boundary located at $20^{\circ} \mathrm{E}$, as shown in Fig. 6. The computational grid has a horizontal resolution of $1 / 20^{\circ} \times 1 / 20^{\circ}$ and 30 sigma layers in the vertical, with a logarithmic distribution near the sea surface, which results in a better representation of the surface mixed layer. Considering the size $(10-14 \mathrm{~km})$ of the internal Rossby radius of deformation for the eastern Mediterranean basin (Robinson et al., 1987), such a model resolution $(\sim 5 \mathrm{~km})$ can marginally resolve the mesoscale eddy activity. Since this version of the ALERMO model is computationally expensive, a coarse version $\left(1 / 10^{\circ} \times 1 / 10,30\right.$ sigma layers $)$ was also developed, in order to perform several sensitivity tests. For both versions of the model, the U.S. Navy Digital Bathymetric Data Base $5\left(1 / 12^{\circ} \times 1 / 12^{\circ}\right)$ was used for building up the model's bathymetry, using bilinear interpolation to map the data onto the model's grid.

\subsection{Nesting technique}

Nesting is a finite-difference technique to simulate a highresolution domain embedded in a coarse resolution model. In our case the coarse resolution model is the global Mediterranean OGCM, which is one-way nested with the ALERMO model (fine grid model). By one-way nesting, we mean that the boundary conditions of the fine grid model are prescribed in some way by external data taken from the coarse resolution model, while the solution of the latter is not modified by the solution of the fine grid model in their common overlapping area. Of major importance in nesting techniques is the conservation of properties between the coarse and fine grid model, and the treatment of fine grid interior noise resulting from several types of incompatibilities between the two models. The OGCM is the Modular Ocean Model (rigid-lid model) implemented within the Mediterranean region with a $1 / 8^{\circ} \times 1 / 8^{\circ}$ horizontal resolution and 31 levels in the vertical. It was integrated for an 8 -year period, using the climatological momentum and heat flux fields developed for the MFSPP project (and presented in Sect. 2 of this paper), plus some additional heat and freshwater correction terms. During the last year of OGCM integration, model prognostic variables are stored in the form of 10-day averages for further use by the ALERMO and three other fine grid models (namely the 


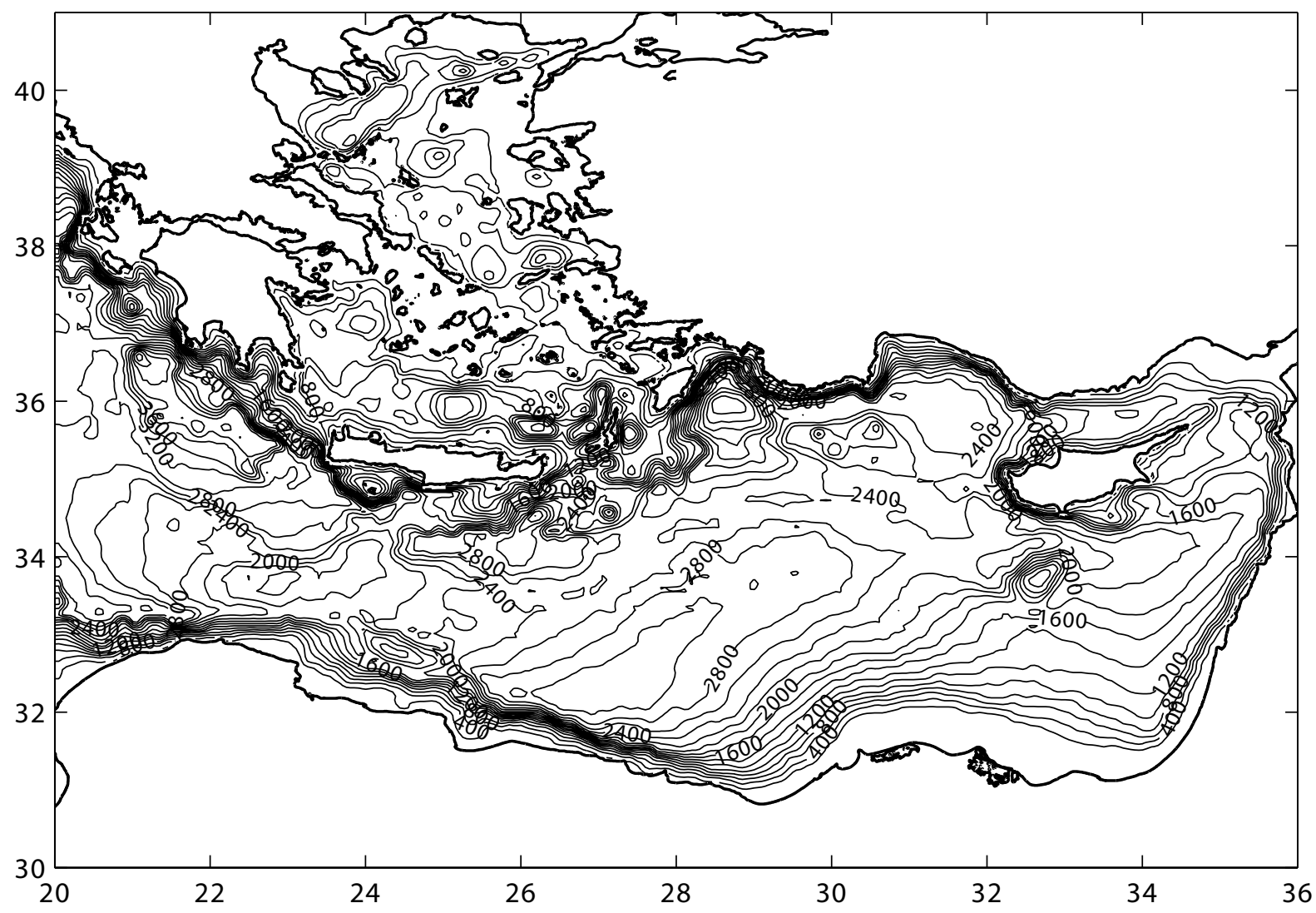

Fig. 6. ALERMO model topography in meters (contour interval: $200 \mathrm{~m}$ ).

western Mediterranean, the Adriatic and the Sicilian straits models) within the Mediterranean region.

The nesting with the global Mediterranean OGCM is applied along the western boundary of ALERMO (located at $20^{\circ} \mathrm{E}$ ). The phenomenology of the area (Robinson et al., 1991) and previous modelling work (Lascaratos and Nittis, 1998) suggest that this is a very important boundary for the water mass exchange (inflowing waters of Atlantic origin and outflowing LIW waters) of the Levantine basin and thus, to a large extent controls both the general and the thermohaline circulation of the area.

The nesting between the two models involves the variables $U_{C}, V_{C}$ (zonal and meridional velocity components), $T_{C}, S_{C}$ (temperature and salinity) and $n_{C}$ (the sea surface height as computed from the surface pressure of the rigid lid model; Pinardi et al., 1995) of the coarse grid model (OGCM) and the prognostic variables $\bar{U}_{F}, \bar{V}_{F}$ (the external mode zonal and meridional velocity components), $U_{F}, V_{F}$ (the internal mode zonal and meridional velocity components), $T_{F}$, $S_{F}$, and $n_{F}$ (free surface elevation) of the fine grid model (ALERMO). During the ALERMO model run, the OGCM 10-day averaged variables $U_{C}, V_{C}, T_{C}, S_{C}$, and $n_{C}$, are interpolated onto the $y-z$ open boundary section of ALERMO at each time step. The interpolated variables are denoted here as $U_{C}^{I N T}, V_{C}^{I N T}, T_{C}^{I N T}, S_{C}^{I N T}$, and $n_{C}^{I N T}$, respectively. Inter- polation in time is linear. The spatial interpolation is bilinear for all OGCM model variables, with the additional constraint of volume conservation through the open boundary. The volume conservation constraint is due to the fact that this particular open boundary section (and any other section that starts and ends to the mainland) in the OGCM is constrained to sustain a zero net volume transport due to the rigid lid model physics. As a result, the interpolated field $U_{C}^{I N T}$ is corrected in such a way that it guarantees volume conservation between the coarse and the fine grid model:

$\int_{y_{1}}^{y_{2}} \int_{-H}^{0} U_{C}^{I N T} d z d y=0$,

where $y_{1}, y_{2}$ are the extremes of the open boundary section, while $H$ is the ALERMO bathymetry at the open boundary.

\subsubsection{OBCs for the external mode}

The condition we use for the normal barotropic velocity (external mode) at the open boundary of ALERMO is a modified Flather (1976) condition that efficiently allows for interior disturbances - due to possible mismatches between coarse and nested values - to pass out through the lateral boundary. The Flather boundary condition initially proposed for tidal 


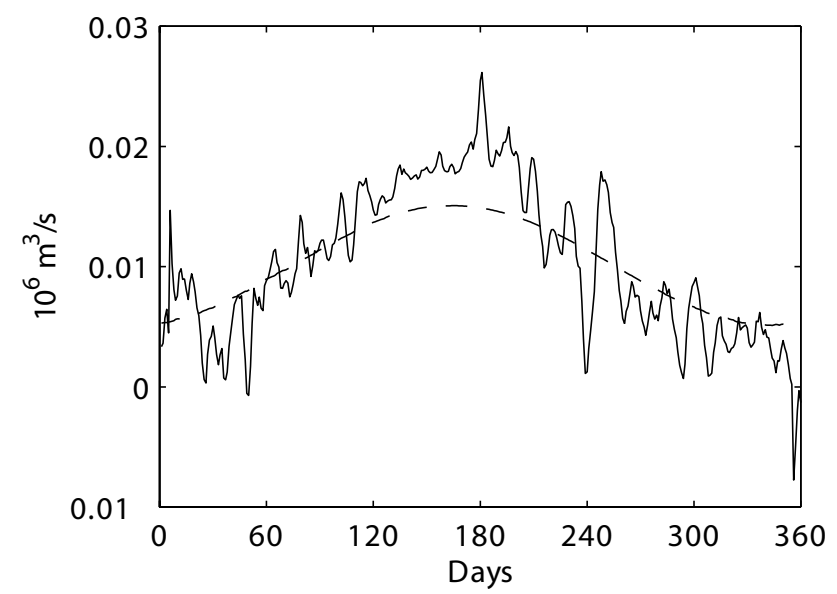

Fig. 7. Net volume transport time series at ALERMO's open boundary (continuous line) and volume discharge into the Aegean Sea due to the Dardanelles and river runoff (dashed line). Positive values of volume transport denote ouflow from the model domain. Units are $106 \mathrm{~m}^{3} / \mathrm{s}$.

models combines a Sommerfeld-type radiation condition:

$$
\frac{\partial n}{\partial t}-\sqrt{g H} \frac{\partial n}{\partial x}=0
$$

with a one-dimensional version of the continuity equation:

$$
\frac{\partial[(H+n) \bar{U}]}{\partial x}+\frac{\partial n}{\partial t}=0
$$

to yield a boundary condition for the normal barotropic velocity $\bar{U}_{F}$ of ALERMO:

$\bar{U}_{F}=\frac{H}{H+n_{F}} \bar{U}_{F}^{I N T}+\frac{\sqrt{g H}}{H+n_{F}}\left(n_{c}^{I N T}-n_{F}\right)$,

where

$\bar{U}_{F}^{I N T}=\frac{1}{H} \int_{-H}^{0} U_{C}^{I N T} d z$.

A Sommerfeld boundary condition does not, in general, respect volume conservation. Due to this fact, one is forced to apply volume conservation constraints (as done in Marchesiello et al., 2001) in cases of significant imbalances between the net volume transport at the open boundary and the time variation of the total volume of the modelling domain.

In our case, as shown in Fig. 7, the net volume transport at the open boundary of ALERMO closely balances on the yearly basis the net inflow to the Aegean Sea due to Dardanelles (mainly) and river runoff. As a result, the mean sea level (not shown) does not show any systematic drift. Thus, no additional constraint is applied to the barotropic flow at the open boundary.

The tangential barotropic velocity at the open boundary is directly prescribed from the OGCM:

$\bar{V}_{F}=\bar{V}_{C}^{I N T}$.

\subsubsection{OBCs for the internal mode}

The internal mode velocities $U_{F}$ and $V_{F}$ (normal and tangential) at the open boundary of ALERMO are directly prescribed from the OGCM:

$U_{F}=\frac{H}{H+n_{F}} U_{C}^{I N T} \quad V_{F}=V_{C}^{I N T}$,

where the factor $H /\left(H+n_{F}\right)$ guarantees volume continuity.

\subsubsection{OBCs for temperature and salinity}

To update the temperature and salinity profiles $T_{F}$ and $S_{F}$ at the open boundary of ALERMO, we use an upstream advection scheme whenever the normal velocity is directed outwards from the modelling area:

$\frac{\partial T_{F}}{\partial t}+U_{F} \frac{\partial T_{F}}{\partial x}=0 \quad \frac{\partial S_{F}}{\partial t}+U_{F} \frac{\partial S_{F}}{\partial x}=0 \quad U_{F}<0$.

In cases of inflow through the open boundary, temperature and salinity are prescribed directly from the interpolated OGCM temperature and salinity profiles $\left(T_{C}^{I N T}, S_{C}^{I N T}\right)$ :

$T_{F}=T_{C}^{I N T} \quad S_{F}=S_{C}^{I N T} \quad U_{F}>0$.

\subsubsection{OBC for the free surface elevation}

For the specification of the free surface elevation at the open boundary of ALERMO, we have adopted a zero-gradient condition:

$\frac{\partial n_{F}}{\partial x}=0$.

\subsection{Initial data}

The ALERMO model is initialized directly from the OGCM model results obtained during the eighth year of its perpetual integration. Temperature, salinity, velocity (internal/external) and sea surface height fields are all specified during the initialization process from the OGCM. In order to reduce the initial shock of the model as much as possible, we decided to initialize ALERMO from summer average conditions (15 August). The OGCM model results were mapped onto ALERMO's grid, using bilinear interpolation in the horizontal and linear in vertical. Extrapolation took place only in limited areas along the northeastern coasts of Greece, within the Cyclades region and adjacent to the Asia Minor coasts, due to the coarse representation of these areas in the OGCM. The adjustment phase of the ALERMO model lasts for approximately 10-15 days and involves mainly the barotropic circulation along the coastal areas of Asia Minor and northern Greece. Such a behaviour can be attributed to the extrapolation of the OGCM values in these areas, which then triggers spurious flow divergences. By day 20 the flow field is already smooth, as can be seen in the free surface elevation field presented in Fig. 8b. In Fig. 8a we show for comparison the sea surface elevation as deduced from the OGCM corresponding to 5 September. It is evident that in order to 

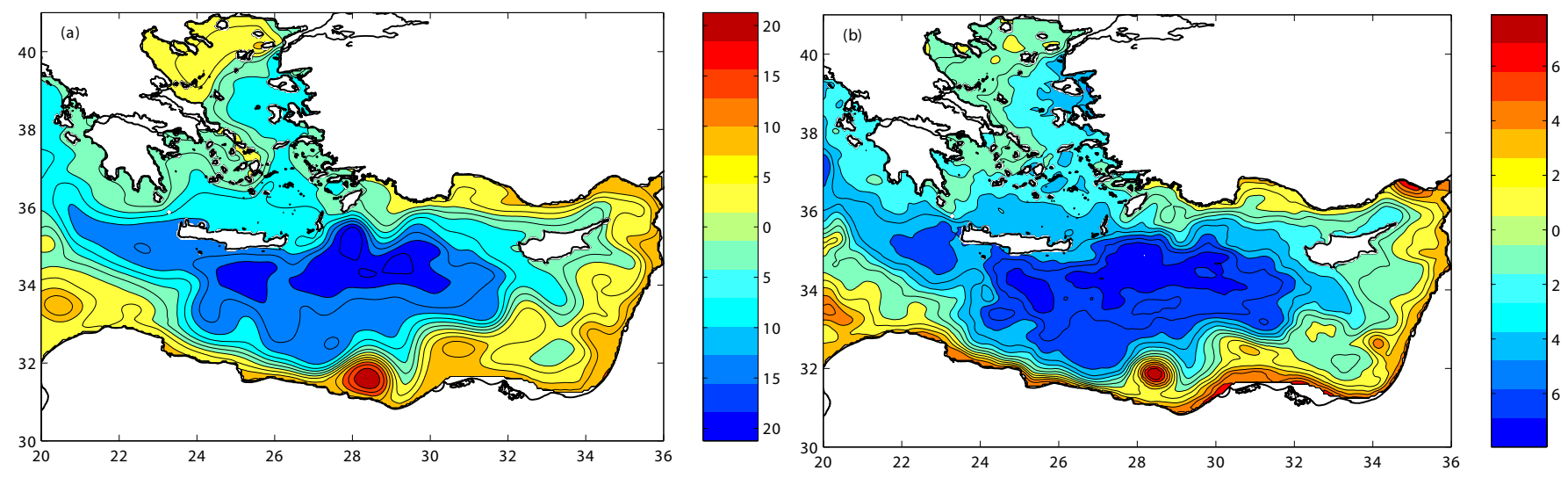

Fig. 8. (a) OGCM sea surface elevation field (5 September) as mapped onto ALERMO's domain (b) ALERMO free surface elevation after 20 days of climatological integration (units are $\mathrm{cm}$ ).

decrease the duration of the adjustment phase of the model as much as possible, more sophisticated techniques should be used in order to extrapolate, when necessary, the coarse model data onto the fine grid.

\subsection{Surface boundary conditions}

\subsubsection{Momentum boundary condition}

The momentum boundary condition at the surface takes the form:

$\left.\rho_{0} K_{M} \frac{\partial \boldsymbol{u}_{h}}{\partial z}\right|_{z=0}=\boldsymbol{\tau}$

where $\boldsymbol{\tau}$ is the wind stress provided by ECMWF's perpetual year monthly climatology, as described in Sect. 2.

\subsubsection{Heat flux boundary condition}

For the heat flux boundary condition at the surface we assume:

$$
\left.\rho_{0} c_{p} K_{H} \frac{\partial T}{\partial z}\right|_{z=0}=Q_{T}+c_{a}\left(T^{*}-T\right)
$$

where $Q_{T}$ is the surface total heat flux field diagnosed from the eighth year of the OGCM climatological run. The term $c_{a}\left(T^{*}-T\right)$ appearing in Eq. (20) acts as a further adjustment of the diagnosed OGCM surface heat flux to the ALERMO's modelling domain. Such an adjustment is justified considering the possible climatic drift of the OGCM and the extrapolation taking place in coastal areas (especially within the north Aegean Sea) when the OGCM fields are mapped onto ALERMO's domain. The $T^{*}$ fields are taken from MODBMED4 SST seasonal climatology (Brasseur et al., 1996), while $c_{a}$ is set to $5 \mathrm{Wm}^{-2} \mathrm{C}^{-1}$.

The OGCM total heat flux field is originally provided as 10-day averages and it is then linearly interpolated in time at each time step of the ALERMO model integration. The OGCM perpetual integration experiment has been forced with the Kondo-Bignami heat flux data set, plus an additional heat flux correction term $c_{0}\left(T^{*}-T_{O G C M}\right)$, where $c_{0}=25 \mathrm{Wm}^{-2} \mathrm{C}^{-1}$. The Kondo-Bignami data set, as already mentioned in Sect. 2, corresponds to a strongly positive $\left(+17.3 \mathrm{Wm}^{-2}\right)$ annual heat budget for the Mediterranean region. This data set is then adjusted in the course of the OGCM climatological integration to yield net heat flux fields - as diagnosed during the eighth year of the OGCM simulation - corresponding to a global Mediterranean annual heat budget equal to $-4.9 \mathrm{Wm}^{-2}$.

\subsubsection{Salinity boundary condition}

The salinity boundary condition at the surface is as follows:

$$
\left.K_{H} \frac{\partial S}{\partial z}\right|_{z=0}=S(E-P)+c_{2}\left(S^{*}-S\right)
$$

where $S$ is the model's sea surface salinity. The evaporation rate $E$ was calculated from the latent heat flux $Q_{e}$, as provided by the Kondo-Bignami climatological data set:

$E=\frac{Q_{e}}{\rho L_{V}}$.

In the above expression $L_{V}$ is taken to be equal to $2.5008 \times$ $10^{6} \mathrm{~J} / \mathrm{kg}$, and $\rho=1023 \mathrm{kgm}^{-3}$ is the density of seawater. The precipitation rate $P$ is obtained from the Jaeger (1976) monthly precipitation climatology, initially mapped on a $5^{\circ} \times$ $2.5^{\circ}$ grid. The correction term $c_{2}\left(S^{*}-S\right)$ accounts for the imperfect knowledge of $E-P$ (especially of the precipitation rates). In this term $S^{*}$ is the seasonal MODB-MED4 sea surface salinity, and $c_{2}$ has been set (upon sensitivity studies) equal to $0.7 \mathrm{~m} /$ day.

\subsection{Parameterization of the Dardanelles outflow and river runoff}

The Dardanelles outflow into the Aegean Sea is a dominant factor for the freshwater budget of the basin, providing approximately $300 \mathrm{~km}^{3}$ of brackish water on an annual basis. 

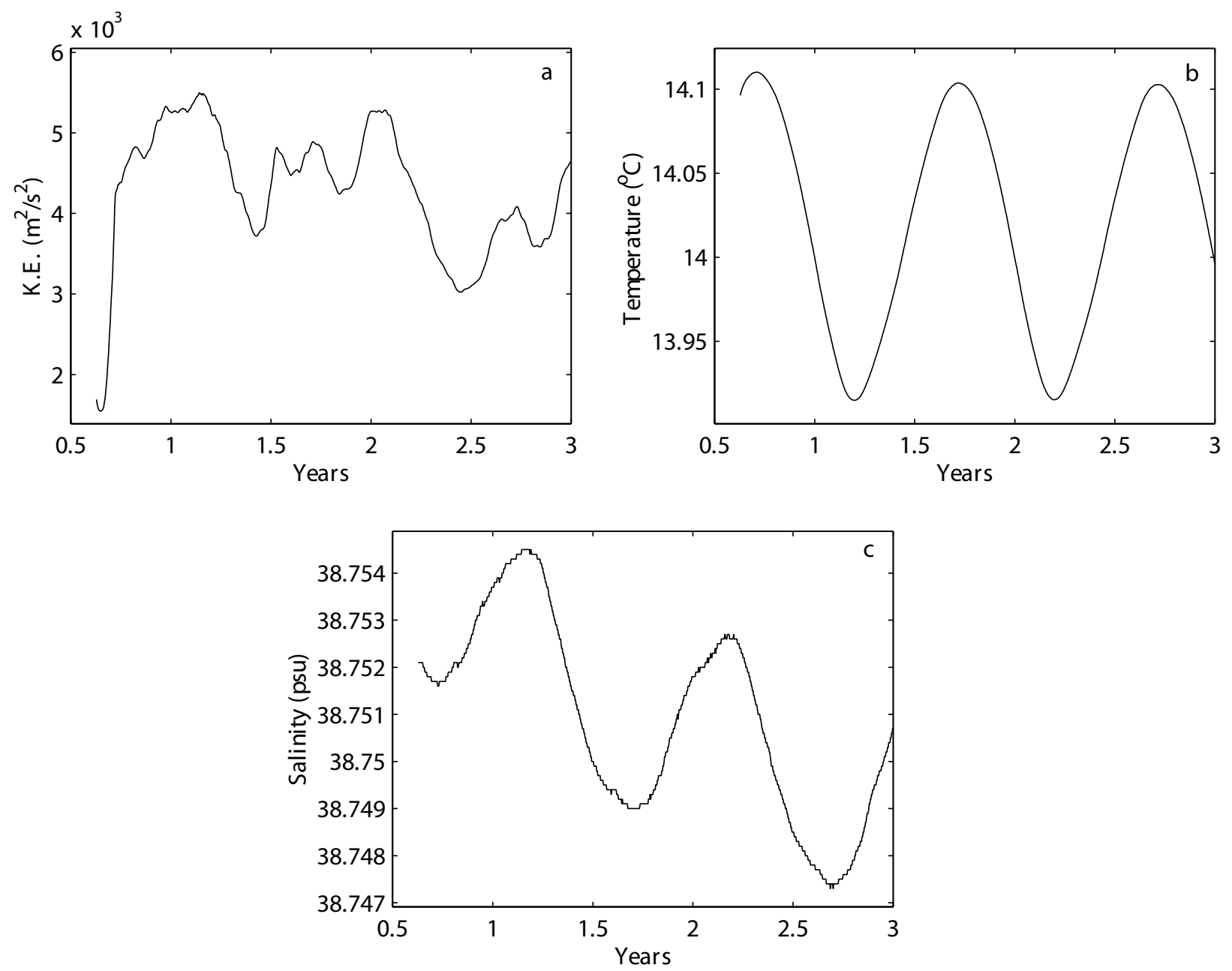

Fig. 9. Basin averaged time series of (a) kinetic energy (b) temperature and (c) salinity, corresponding to ALERMO's climatological integration.
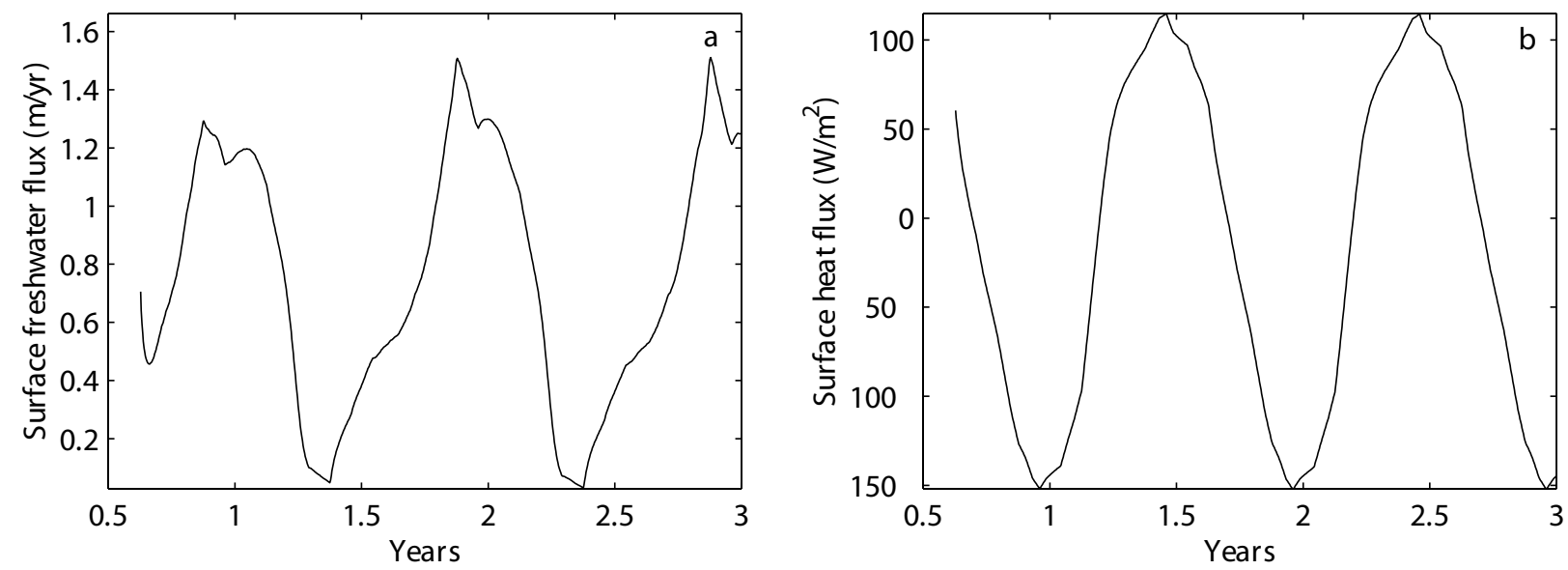

Fig. 10. Basin averaged time series of (a) diagnosed surface freshwater flux and (b) diagnosed surface total heat flux, corresponding to ALERMO's climatological integration. 



Fig. 11. (a) ALERMO's subsurface velocity field $(30 \mathrm{~m})$ during February, (b) as in Fig. 11a but for August (c) as in Fig. 11a but for the OGCM model (d) as in Fig. 11b but for the OGCM model.

The main Greek rivers (Axios, Aliakmonas, Gallikos, Pinios, Sperchios, Evros, Strimonas and Nestos), on the other hand, with a total runoff of $\sim 19 \mathrm{~km}^{3} / \mathrm{yr}$, have a lesser contribution to the freshwater budget. Even lower is the contribution of the Turkish rivers, with a total runoff of $\sim 5 \mathrm{~km}^{3} / \mathrm{yr}$ (Poulos et al., 1997).

ALERMO includes parameterization of Dardanelles' net outflow into the Aegean Sea and the runoff of the major rivers of the Thermaikos Gulf (Aliakmonas, Axios and Loudias). The net annual Dardanelles outflow to the Aegean Sea is considered to be $10^{4} \mathrm{~m}^{3} / \mathrm{s}$, with a seasonal modulation of $5 \times 10^{3} \mathrm{~m}^{3} / \mathrm{s}$. Maximum values are reached during mid-July, while the minimum is in mid-January. The salinity of this water outflow is set equal to 28.3 psu throughout the year. The Thermaikos Gulf rivers' runoff is specified according to daily climatological values, as provided by the Greek Ministry of Agriculture. It ranges from between 28 and $324 \mathrm{~m}^{3} / \mathrm{s}$, with a minimum at the end of July and a maximum in February.

The water discharge $Q_{j}$ (where $j$ denotes the grid point where the discharge is introduced and $Q_{j}$ has units $\mathrm{L}^{3} / \mathrm{T}$ ) for the Dardanelles outflow or the rivers' runoff parameterizations, is treated as a point source in the two-dimensional continuity equation, which becomes:

$$
\frac{\partial n}{\partial t}+\frac{\partial D u}{\partial x}+\frac{\partial D v}{\partial y}=\frac{Q_{j}}{A_{j}}
$$

where $D=H+n$ and $A_{j}=\Delta x_{j} \Delta y_{j}$.

Finally, the water surplus due to the rivers' runoff and the Dardanelles net outflow has the same temperature of the model's top layer at the specified grid point, whereas its salinity, as already mentioned, is 28.3 psu for Dardanelles and 0.0 psu for the Gulf of the Thermaikos rivers.

This parameterization has been successfully used by Kourafalou et al. (1996) for the study of rivers' discharge on continental shelves. We are aware that such a parameterization for the Dardanelles inflow/outflow tends to underestimate the freshwater input into the north Aegean Sea, as compared with a lateral flux boundary condition (open boundary condition). However, due to the inadequate knowledge of inflow and outflow velocities at the Bosporus straits on a climatological basis, we preferred specifying the net water discharge (which is more accurately known) rather than using an open boundary condition. 


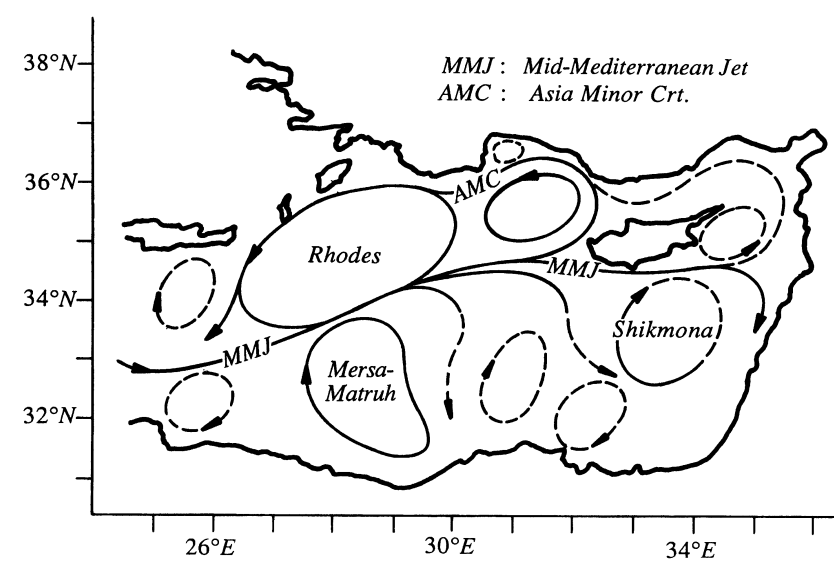

Fig. 12. Schematic upper thermocline general circulation (redrawn from Robinson et al., 1991).

\subsection{Model results}

Starting from the late summer initial conditions (15 August), the model was integrated for two and one-half successive years with open boundary conditions, initial data, forcing input and Dardanelles/river-runoff parameterizations as described in Sects. 3.2, 3.3, 3.4 and 3.5, respectively. The basin's averaged kinetic energy of the model (shown in Fig. 9a) is quasi-stabilized after the second year of the perpetual integration. The same holds for the basin's averaged temperature and salinity of the area (shown in Figs. 9b and 9c), although the basin's averaged salinity time series is showing a decreasing trend. The time series of the diagnosed freshwater flux $(E-P+$ correction $)$ and total heat flux $\left(Q_{T}+\right.$ correction) at the surface (shown in Figs. 10a and 10b) are characterized by an average value of $0.72 \mathrm{~m} / \mathrm{yr}$ and $-10.4 \mathrm{~W} / \mathrm{m}^{2}$ during the last year of integration, respectively.

\subsubsection{Circulation patterns}

In Figs. 11a and $11 \mathrm{~b}$ we present the subsurface $(30 \mathrm{~m})$ winter (mid-February) and summer (mid-August) circulation patterns corresponding to the second year of the climatological integration of the model. The circulation patterns suggest that the model can successfully reproduce all the main general circulation characteristics of the area (Mid Mediterranean Jet, Asia Minor Current, Rhodes cyclonic gyre, Mersa-Matruh and Shikmona anticyclonic gyres), revealed by the synthesis of the POEM data set (see Fig. 12 adapted from Robinson et al., 1991). Both winter and summer circulation patterns are very rich in mesoscale features, which are mainly intensified during the summer period. In Figs. $11 \mathrm{c}$ and $11 \mathrm{~d}$ we show for intercomparison the circulation patterns corresponding to the eighth year of the OGCM climatological run. It is evident from such an intercomparison that ALERMO is able to reproduce the general circulation picture as provided by the OGCM and enrich it with various mesoscale structures, especially in the easternmost Levantine basin.
Important seasonal variability characterizes the easternmost Levantine basin and the southern central Levantine. In the former, we see the recurrence of the Shikmona anticyclone between winter and summer, while in the latter the Mersa-Matruh gyre exhibits large variations in strength, shape and position. The Mid Mediterranean Jet (MMJ) is well formed and shows significant seasonal variations in its pathways.

During winter, MMJ flows along the northern border of the Mersa-Matruh gyre. Along its eastward path, several meanderings take place, resulting in some cases in anticyclonic eddy detachments to the north of the jet. Such a detachment process of an anticyclonic eddy is shown in Fig. 13 for four successive snapshots taken every ten days, starting from 20 January. The main part of MMJ departs from the African coast at approximately $25^{\circ} \mathrm{E}$. Moreover, a cyclonic eddy located near the African coast at $29^{\circ} \mathrm{E}$ completely blocks the coastal branch of MMJ, which, in turn, feeds the MMJ branch along the northern border of Mersa-Matruh. As a result, the northern branch reinforces and starts meandering to the north at $30^{\circ} \mathrm{E}$ (Fig. 13a). Gradually, the meandering becomes very steep (Figs. 13b and c) and finally leads to the detachment of an anticyclonic eddy, which then slowly moves to the north. The signal of this eddy is clearly evident at 300 $400 \mathrm{~m}$, while below this depth it is absent. At the beginning of March (Fig. 14a) the anticyclone moves very close to the MMJ and 20 days latter (Fig. 14b) it has been completely recaptured. Wintertime meandering of the MMJ within the eastern Levantine basin is not very pronounced. After its entrance, it moves directly towards the Israeli coasts, where it turns to the west and encircles the Shikmona anticyclone. It subsequently moves to the northeast, enters the Lattakia basin and finally feeds the Asia Minor current (AMC).

During summer the MMJ remains hugged to the African coast up to $29^{\circ} \mathrm{E}$, and the Mersa-Matruh gyre, appearing now as a three-lobe structure (Ozsoy et al., 1993; MalanotteRizzoli et al., 1999), is completely to the north of the jet. During this period of the year, Mersa-Matruh expands spatially and strengthens. As a result, the Rhodes gyre is squeezed to the north. The MMJ is not showing any meandering until it reaches the easternmost Levantine continental shelf, where at approximately north of the Israeli coasts, it bifurcates into two branches. One branch flows to the northwest and the other continues to the north along the eastern Levantine continental shelf. The northwestern branch, along its path, forms a series of two cyclones and finally an anticyclone to the southwest of Cyprus and then turns to the east to flow towards the eastern Levantine continental shelf following the $1000 \mathrm{~m}$ isobath to the south of Cyprus. This eastward current merges with the north branch flowing along the eastern Levantine continental shelf at $34^{\circ} \mathrm{N}$, and they both form two extended anticyclones east of Cyprus within the Lattakia basin to finally feed the AMC.

In Fig. 15 we show a close-up of the Aegean circulation during the winter and summer periods. During the cold season the AMC enters the Aegean Sea mainly through the Rhodes-Karpathos straits and secondarily through the Crete- 

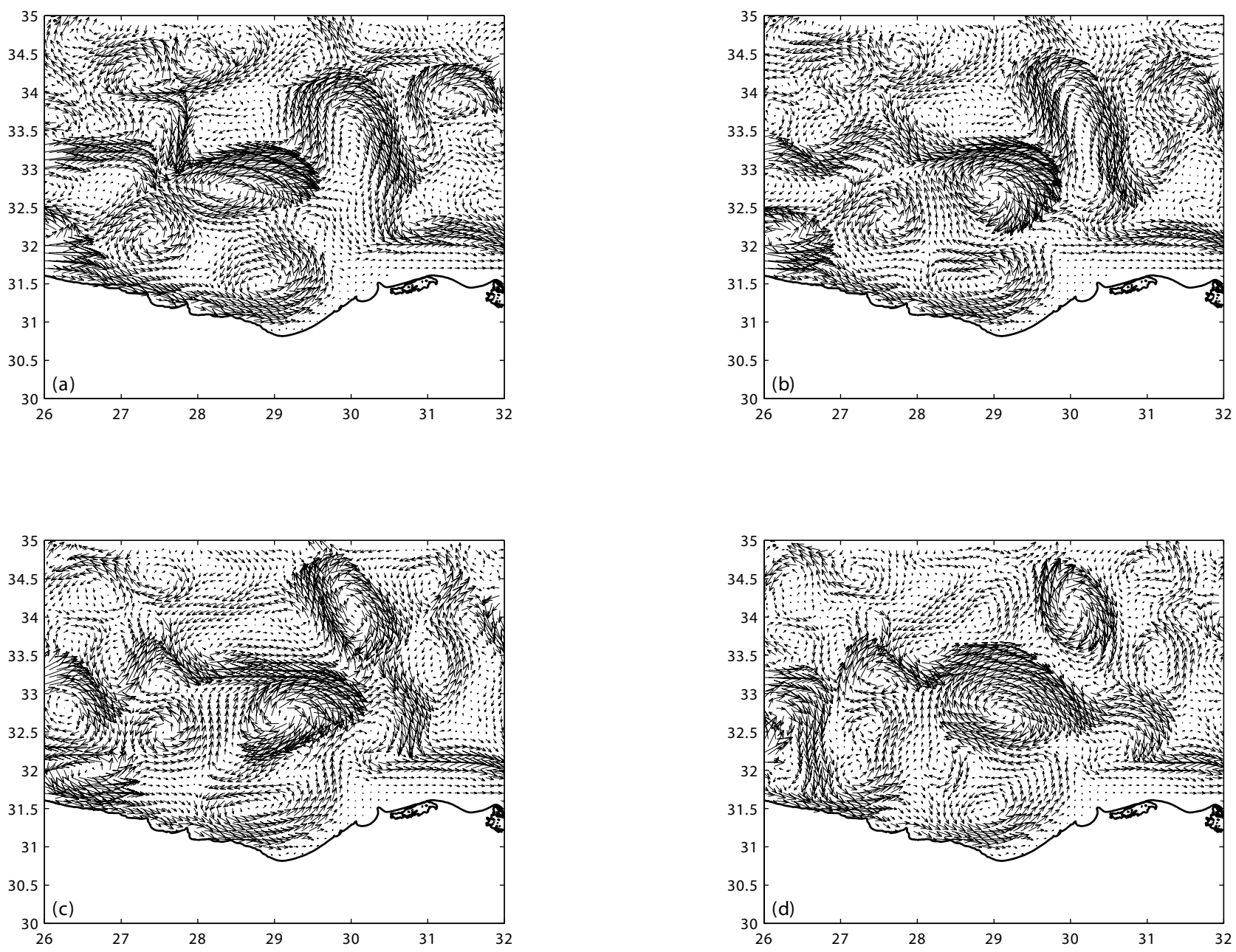

Fig. 13. Evolution of ALERMO's subsurface ( $30 \mathrm{~m}$ ) velocity field within the geographical area $30^{\circ}-35^{\circ} \mathrm{N}, 26^{\circ}-32^{\circ} \mathrm{E}$ for (a) 20 January (b) 30 January (c) 10 February and (d) 20 February.

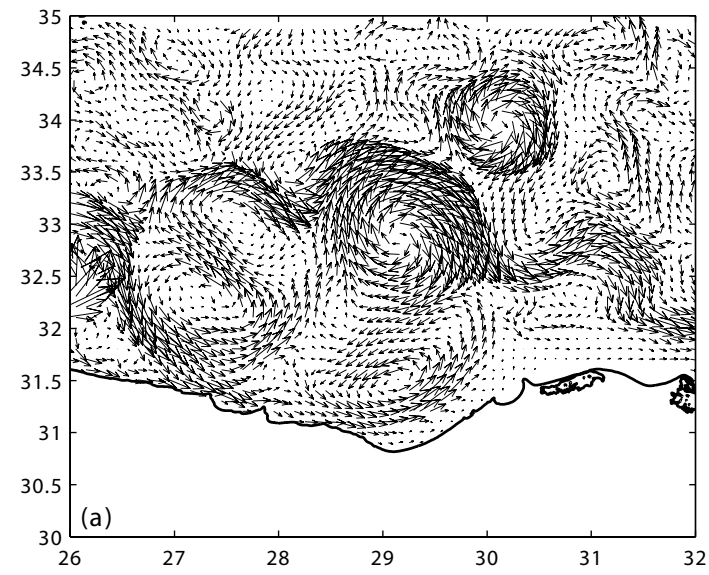

Fig. 14. As in Fig. 13 but for (a) 10 March and (b) 30 March.

Kassos straits. The main part of this flow follows a westward path, forming a dipole to the north of Crete and a large-scale cyclonic circulation within the Mirtoan basin. The Levan-

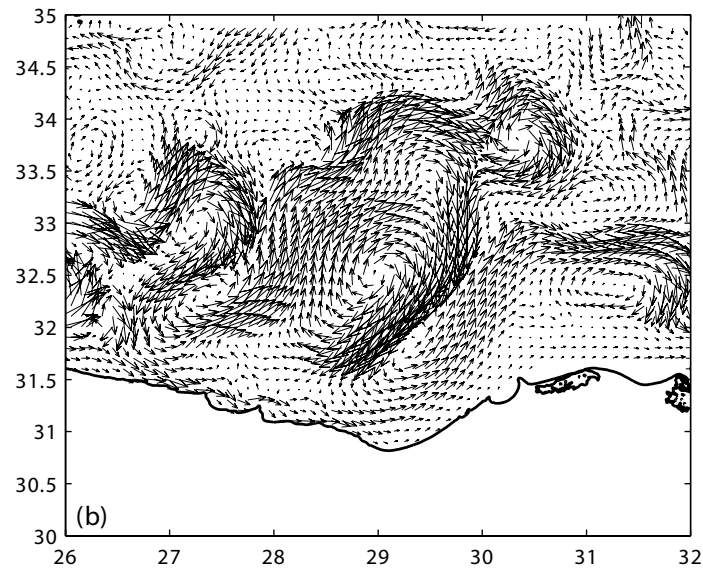

tine origin waters finally exit through the Kithira-Antikithira straits. The north and central Aegean during this period of the year are not showing any remarkable mesoscale variabil- 
ity. However, the situation changes during summer, where a rich mesoscale field is present. We can point out the presence of a well-formed anticyclone to the south of Mount Athos (Mount Athos anticyclone) and a rather intense anticyclonic eddy positioned to the north of Andros island. The latter forms during early summer and gradually develops in size and strength. When it is positioned exactly to the north of the Evia-Andros passage, it can partially block the less saline waters of the Black Sea origin from passing through. However, from autumn onwards this anticyclone spins down. During the warm season, the Levantine waters enter the Aegean Sea mainly through the Rhodes-Asia Minor passage and move directly to the north, possibly to compensate for the increased outflow from the Dardanelles. These saline waters intruding into the north Aegean form a prominent frontal area upon merging with the brackish waters exiting the Dardanelles and flowing to the southwest. In the Cretan Sea, the dipole to the north of Crete is still present, but less intense due to the weakening of the westward zonal current.

\section{Conclusions}

The purpose of this work was twofold. Our first goal was to develop a suitable surface boundary conditions monthly data set, to be used for climatological integrations by the various models involved within the MFSPP modelling network. To this end we used the ECMWF 1979-1993 atmospheric parameters data set and several well-tuned bulk formulae to achieve the optimum in terms of a surface heat and freshwater budget set of boundary conditions. The success of various models simulations, forced with this new data set, in depicting known and robust characteristics of the Mediterranean general circulation, is at least a good check for its validity.

The second goal of this study was to implement and test an eddy resolving numerical model for the eastern Mediterranean basin, one-way nested with the coarse resolution OGCM. To this end, we implemented a high-resolution version of POM model to this area and subsequently nested it with the global Mediterranean OGCM. The nesting technique that was adopted was based on volume transport conservation principles between the two models and radiativenesting boundary conditions. Although the idea behind such boundary conditions is rather simple, our results indicate its effectiveness in coupling the ALERMO model with the OGCM on the climatological basis. On going work with the ALERMO model (to be presented in a forthcoming paper), using high-frequency (6-h) atmospheric forcing parameters and daily open boundary conditions updates, give very promising results about the robustness of this particular nesting technique.

The results obtained so far indicate that the ALERMO model nested to the OGCM on the climatological basis can successfully reproduce the coarse model solution and at the same time modify this solution in terms of adding fine resolution structures. Several mesoscale structures, like the three-
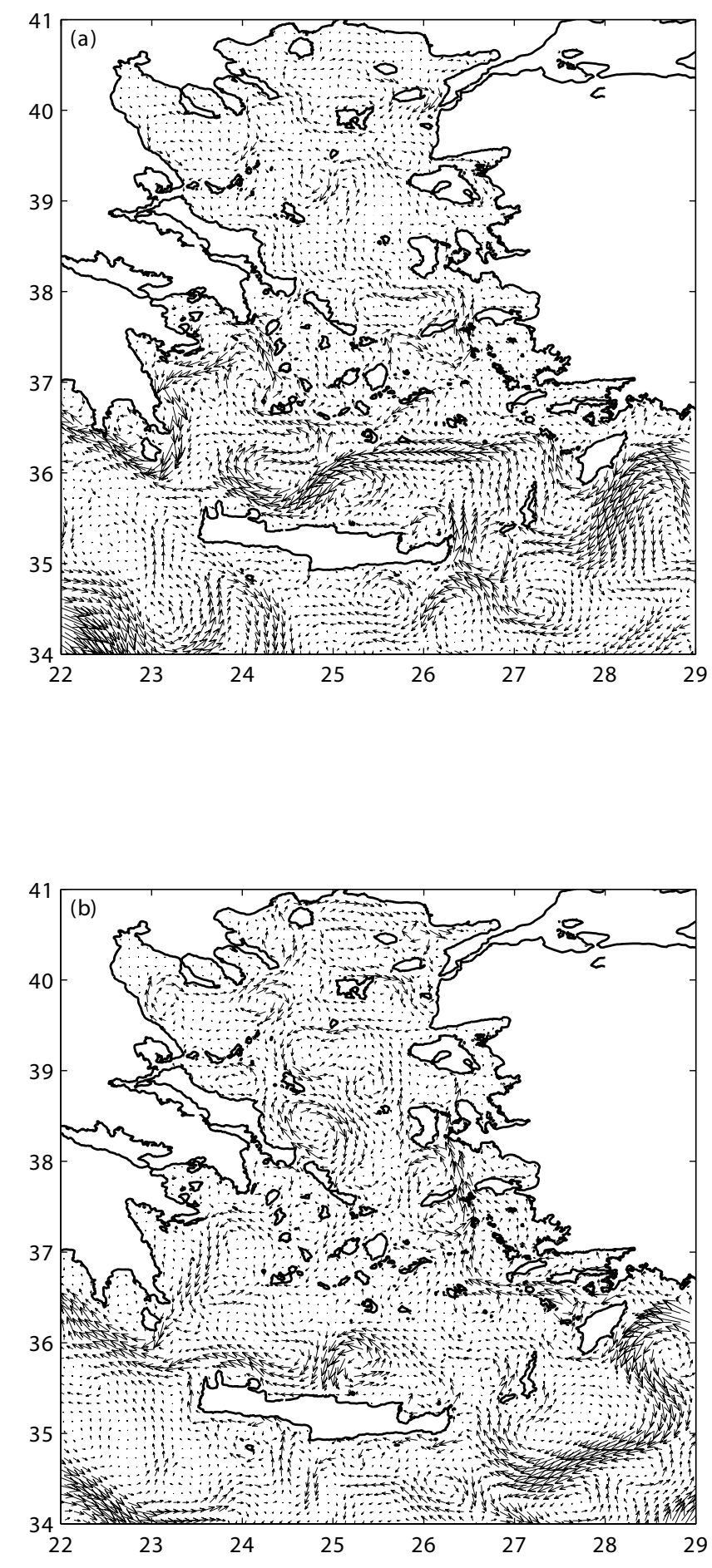

Fig. 15. Aegean Sea subsurface $(30 \mathrm{~m})$ circulation picture as deduced from ALERMO's climatological run: (a) for February and (b) for August.

lobe Mersha-Matruh and the rich eddy field within the easternmost Levantine basin, have been captured for the first time to our knowledge by a numerical model of the area. However, towards a real-time prediction system of the eastern Mediterranean, which is one of the ultimate goals of 
the MFSPP project, more elaborate work is needed in terms of model initialization, boundary conditions refinement and data assimilation algorithms.

Acknowledgements. This work has been supported by the MFSPP EU-RTD project. We would like to express our gratitude to Dr. M. Zavatarelli, Dr. S. Sofianos and the whole MFSPP group for fruitful discussions, suggestions and critique to the work. We acknowledge the anonymous reviewers for their constructive criticisms to the previous version of the manuscript. Reynolds SST data were provided by the NOAA-CIRES Climate Diagnostics Center, Boulder, Colourado, from their Web site at http://www.cdc.noaa.gov/.

\section{References}

Blumberg, A. F. and Mellor, G. L.: Diagnostic and prognostic numerical circulation studies of the South Atlantic Bight, J. Geophys. Res., 88, 4579-4592, 1983.

Blumberg, A. F. and Mellor, G. L.: A description of a threedimensional coastal ocean circulation model, in: ThreeDimensional Coastal Ocean Circulation Models, (Ed) Heaps, N. S., Coastal Estuarine Sci., vol. 4, 1-16, AGU, Washington, D.C, 1987.

Bignami, F., Marullo, S., and Santoleri, R.: Longwave radiation budget in the Mediterranean Sea, J. Geophys. Res., 100, 25012514, 1995.

Brasseur, P., Beckers, J. M., Brankart, J. M., and Schoenauen, R.: Seasonal temperature and salinity fields in the Mediterranean Sea: climatological analyses of a historical data set, Deep-Sea Res. 43, 159-192, 1996.

Budyko, M. I.: Atlas of the heat balance of the Earth. Glabnaia Geofiz. Observ, 1963.

Castellari, S., Pinardi, N., and Leaman, K.: A model study of airsea interactions in the Mediterranean Sea, J. Marine Systems 18, 89-114, 1998.

Drakopoulos, P. G. and Lascaratos, A.: Modelling the Mediterranean Sea: climatological forcing, J. Marine Systems 20, 157173, 1997.

Ezer, T. and Mellor, G. L.: A numerical study of the variability and the separation of the Gulf Stream, induced by surface atmospheric forcing and lateral boundary flows, J. Phys. Oceangr., 22, 660-682, 1992.

Flather, J.: A tidal model of the northwest European continental shelf, Mem. Soc. R. Sci. Liege, Ser. 6, 10, 141-164, 1976.

Galperin, B. and Mellor, G. L.: A time-dependent, threedimensional model of the Delaware Bay and River. Part 1: Description of the model and tidal analysis, Estuarine, Coastal and Shelf Sci., 31, 231-253, 1990a.

Galperin, B. and Mellor, G. L.: A time-dependent, threedimensional model of theDelaware Bay and River. Part 2: Three-dimensional flow fields and residual circulation, Estuarine, Coastal and Shelf Sci., 31, 255-281, 1990b.

Garrett, C., Outerbridge, R., and Thompson, K.: Interannual variability in Mediterranean heat and buoyancy fluxes, J. Climate 6, 900-910, 1993

Gill, A. E.: Atmosphere-Ocean Dynamics, Academic Press, New York, 1982.

Golnaraghi, M.: Dynamical studies of the Mersa Matruh Gyre: intense meander and ring formation events, Deep-Sea Research II, 40, 1247-1267, 1993.
Hellermann, S. and Rosenstein, M.: Normal wind stress over the world ocean with error estimates, J. Phys. Oceanogr. 13, 1093 1104, 1983.

Horton, C., Clifford, M., Schmitz, J., and Kantha, L. H.: A real-time oceanographic nowcast/forecast system for the Mediterranean Sea, J. Geophys. Res., 102, 25 123-25 156, 1997.

Jaeger. , L.: Monatskarten des Niederschlags fur die ganze Erde. Berichte des Deutschen Wetterdienstes 18 (139), 1-38, 1976.

Jakob, C.: Cloud cover in the ECMWF reanalysis, J. Climate, 12, 947-959, 1999.

Kondo, J.: Air-sea bulk transfer coefficients in diabatic conditions, Boundary-Layer Meterol., 9, 91-112, 1975.

Kourafalou, V. H., Oey, L.-Y., Wang, J. D., and Lee, T. N.: The fate of river discharge on the continental shelf, 1, Modeling the river plume and the inner shelf coastal current, J. Geophys. Res., 101, 3415-3434, 1996.

Lascaratos, A. and Nittis, K.: A high resolution three-dimensional numerical study of intermediate water formation in the Levantine Sea, J. Geophys. Res., 103, 18 497-18 511, 1998.

Lascaratos, A., Roether, W., Nittis, K., and Klein, B.: Recent changes in deep water formation and spreading in the eastern Mediterranean: a review, Prog. Oceanogr., 44, 5-36, 1999.

Lowe, P. R.: An approximating polynomial for the computation of saturation vapor pressure, J. Appl. Meteorol. 16, 100-103, 1977.

Malanotte-Rizzoli, P., Manca, B., d'Alcala, M., Theocharis, A., Brenner, S., Budillon, G., and Ozsoy, E.: The Eastern Mediterranean in the $80 \mathrm{~s}$ and in the 90s: the big transition in the intermediate and deep circulations, Dyn. Atmos. Oceans, 29, Issues 2-4, 365-395, 1999.

Marchesiello, P., McWilliams, J. C., and Shchepetkin, A.: Open boundary conditions for long-term integration of regional oceanic models, Ocean Modelling, 3, 1-20, 2001.

Mellor, G. L: Users guide for a three-dimensional, primitive equation, numerical ocean model (July 1998 version), Prog. in Atmos. and Ocean. Sci, Princeton University, 1998.

Mellor, G. L. and Blumberg, A. F.: Modeling vertical and horizontal diffusivities with the sigma coordinate system, Mon. Wea. Rev., 113, 1379-1383, 1985.

Mellor, G. L. and Ezer, T.: A Gulf Stream model and an altimetry assimilation scheme, J. Geophys. Res., 96, 8779-8795, $1991 \mathrm{a}$.

Mellor, G. L.: An equation of state for numerical models of oceans and estuaries, J. Atmos. Oceanic Technol., 8, 609-611, $1991 \mathrm{~b}$.

Mellor, G. L. and Yamada, T.: Development of a turbulence closure model for geophysical fluid problems, Rev. Geophys., 20, 851$875,1982$.

Miyakoda, K. and Rosati, A.: One-way nested grid models: The interface conditions and the numerical accuracy, Mon. Wea. Rev., 105, 1092-1107, 1977.

Oey, L.-Y., Mellor, G. L., and Hires, R. I.: A three-dimensional simulation of the Hudson-Raritan estuary. Part I: Description of the model and model simulations, J. Phys. Oceanogr., 15, 16761692, 1985a.

Oey, L.-Y., Mellor, G. L., and Hires, R. I.: A three-dimensional simulation of the Hudson-Raritan estuary. Part II: Comparison with observation, J. Phys. Oceanogr., 15, 1693-1709, 1985 b.

Ozsoy, E., Hecht, A., Unluata, U., Brenner, S., Sur, H. I., Bishop, J., Latif, M. A., Rozentraub, Z., and Oguz, T.: A synthesis of the Levantine Basin circulation and hydrography, 1985-1990. DeepSea Research II, 40, 6, 1075-1119, 1993.

Pinardi, N. and Masetti, E.,: Variability of the large-scale general circulation of the of the Mediterranean Sea from observations and modelling, Paleogeography, paleoclimatology, paleoe- 
cology, 158, 153-173, 2000.

Pinardi, N., Korres, G., Lascaratos, A., Roussenov, V., and Stanev, E.: Numerical simulation of the Mediterranean Sea upper ocean circulation, Geophys. Res. Lett., 24, 425-428, 1997.

Pinardi, N., Rosati, A., and Pacanowski, R. C.: The sea surface pressure formulation of rigid lid models. Implications for altimetric data assimilation studies, J. Mar. Systems, 6, 109-119, 1995.

Poulos, S. E., Drakopoulos, P. G., and Collins, M. B.: Seasonal variability in the sea surface oceanographic conditions in the Aegean Sea (Eastern Mediterranean). An Overview, J. Mar. Systems, 13, 225-244.

Reed, R. K.: On estimating insolation over the ocean, J. Phys. Oceanogr. 17, 854-871, 1977.

Reynolds, R. W. and Smith, T. M.: Improved global sea surface temperature analyses using optimum interpolation, J. Climate, 7, 929-948, 1994.

Robinson, A. R. and Golnaraghi, M.: Circulation and dynamics of the Eastern Mediterranean Sea; quasi-synoptic data-driven simulations, Deep-Sea Research II, 40, 1207-1246, 1993.

Robinson, A. R., Golnaraghi, M., Leslie, W. G., Artegiani, A., Hecht, A., Lassoni, E., Michelato, A., Sansone, E., Theocharis, A., and Unluata, U.: The Eastern Mediterranean general circulation: Features, structure and variability, Dyn. Atmos. Oceans, 15, 215-240, 1991.

Robinson, A. R., Hecht, A., Pinardi, N., Bishop, J., Leslie, W. G.,
Rosentraub, Y., Mariano, A. J., and Brenner, S.: Small synoptic/mesoscale eddies: The energetic variability of the Eastern Levantine basin, Nature 327(6118), 131-134, 1987.

Rosati, A. and Miyakoda, K.: A general circulation model for upper ocean simulation, J. Phys. Oceanogr. 18, 1601-1626, 1988.

Roussenov, V., Stanev, E., Artale, V., and Pinardi, N.: A seasonal model of the Mediterranean Sea general circulation, J. Geophys. Res., 100, 13 515-13 538, 1995.

Schiano, M. E., Borghini, M., and Castellari, S.: Climatic features of the Mediterranean Sea detected by the analysis of the longwave radiative bulk formulae, Ann. Geophysicae, 18, 14821487, 2000.

Slutz, R. J., Lubker, S. J. Hiscox, J. D., Woodruff, S. D., Jenne, R. L., Joseph, D. H., Steurer, P. M., and Elms, J. D.: COADS, Comprehensive Ocean-Atmosphere Data Set, Release 1. Available in Climate Research Program, ERL, Boulder, CO, 1985.

Smagorinsky, J.: General circulation experiments with the primitive equations, I, The basic experiment, Mon. Weather Rev., 91, 99164, 1963.

Zavatarelli, M. and Mellor, G. L.: A numerical study of the Mediterranean sea circulation, J. Phys. Oceanogr., 25 (6), 1384-1414, 1995.

Zavatarelli, M. and Pinardi, N.: The Adriatic Sea general circulation: modelling with the Princeton Ocean Model, Annales Geophysicae, 13 (suppl. 2), C251, 1995. 